\title{
МИНЕРАЛЫ Y-LN В КОЛЧЕДАННЫХ РУДАХ ПРОЯВЛЕНИЯ БРАГИНО, ЮЖНАЯ ПЕЧЕНГА, КОЛЬСКИЙ РЕГИОН
}

\section{Компанченко А.А., Волошин А.В., Базай А.В.}

Геологический институт КНЦ РАН, Anamumbl,komp-alena@yandex.ru

Южно-Печенгская структурная зона (ЮПСЗ) является частью нижнепротерозойской рифтогенной структуры Печенга-Имандра-Варзуга, в северо-западной части Кольского региона. Колчеданные руды развиты на участке Брагино, который расположен в осевой части на юго-восточном блоке ЮПСЗ. Центральная его часть представлена метапикробазальтами меннельской толщи. На северном и южном флангах участка развиты вулканогенно-осадочные образования брагинской свиты. В вулканитах, преимущественно за пределами участка, закартированы малые тела диоритов, гранит-порфиров, лампрофиров, сиенитов комплексов брагинских малых тел. По вулканогенноосадочным толщам широко развиты метасоматические образования - кварциты, березиты, листвениты, основные метасоматиты, альбититы [1].

Массивные руды, наиболее распространенные на участке, разделены на три типа в зависимости от содержания сульфидов и вещественного состава. Массивные пирротиновые руды I типа выделены в центральной части рудного тела, состоят на 90-95\% из сульфидов, $90 \%$ из которых приходится на пирротин, остальные - марказит и пирит, халькопирит, молибденит, отсутствует сфалерит. Массивные пирротиновые руды II типа - наиболее распространены на всем участке. Они состоят на $80-85 \%$ из сульфидов, из которых $60 \%$ приходится на пирротин, по $15 \%$ на халькопирит и сфалерит, остальные - марказит, пирит, молибденит, галенит и др. В пирротиновых рудах II типа обнаружены «гнезда», размером $1 \times 1$ м, на $85 \%$ сложенные крупнокристаллическим пиритом с нерудными минералами в интерстициях - третий тип руд - массивные пиритовые. Границы перехода от пирротиновых руд II типа к пиритовым рудам резкие.

В колчеданных рудах участка Брагино, в пирротиновых рудах II типа и пиритовых рудах, были обнаружены реликты некой гидротермальной системы. Она представляет собой будинированные жилки кварц-альбитового состава, в которых локализуются многочисленные представители $\mathrm{Cr}-\mathrm{Sc}-\mathrm{V}$ минерализации (тиванит, ноланит, кульсонит, мусковит-роскоэлит, тортвейтит и др.).

Изучение минералов колчеданных руд проводилось на оптическом микроскопе Axioplan в отраженном поляризованном свете с блоком видиорегистрации. Исследование морфологии, фазовой и внутрифазовой неоднородности минералов проводились при помощи сканирующего электронного микроскопа (CЭM) LEO-1450 с оценкой состава минеральных фаз посредством энергодисперсионного спектрометра (ЭДС) Bkuker XFlash 5010 (ГИ КНЦ РАН). Так же исследования химического состава и неоднородности проводились на СЭМ Hitachi S-3400N с ЭДС Oxford X-Max 20 (pecypcный центр (РЦ) СПбГУ «Геомодель», Санкт-Петербург). Химический анализ однородных зёрен минералов размером более 20 мкм выполнен на электронно-зондовом микроанализаторе Cameca MS-46 в Геологическом институте КНЦ РАН.

Среди минералов Y-Ln ассоциации выявлены представители разных классов: оксиды, фосфаты и силикаты.

\section{Оксиды Y-Ln}

Среди минералов группы кричтонита в колчеданных рудах Брагино установлены давидит(La) $\mathrm{La}(\mathrm{Y}, \mathrm{U}) \mathrm{Fe}_{2}(\mathrm{Ti}, \mathrm{Fe}, \mathrm{Cr}, \mathrm{V})_{18}(\mathrm{O}, \mathrm{OH}, \mathrm{F})_{38}$ и давидит-(Ce) $\mathrm{Ce}(\mathrm{Y}, \mathrm{U}) \mathrm{Fe}_{2}(\mathrm{Ti}, \mathrm{Fe}, \mathrm{Cr}, \mathrm{V})_{18}(\mathrm{O}, \mathrm{OH}, \mathrm{F})_{38}$ [3]. Эти минерады крайне редко образуют индивидуализированные зерна, чаще они находятся в срастании с кричтонитом и сенаитом, иногда в виде мелких выделений сложной конфигурации в кричтонитовом агрегате. Доминирующим катионом обычно выступает La, peже - Ce, следовательно, давидит(La) более распространен. 


\section{Фосфаты Y-Ln}

Ксенотим- $(Y), Y\left(P O_{4}\right)$ встречается в виде ксеноморфных выделений, корродированных кристаллов и насыщенных включениями агрегатов (рис. 1 a, б) в разных типах руд. Ксенотим обладает не только фазовой, но и внутрифазовой неоднородностью, обусловленной неравномерным распределением других редкоземельных элементов. Ha BSE-снимках светлые участки в кристаллах соответствуют зонам с повышенным содержанием Gd, Dy, Er, Yb, Sm (в сумме до 24 мас. \%) и соответствуют формуле $\left(\mathrm{Y}_{0.75} \mathrm{Gd}_{0.08} \mathrm{Dy}_{0.08} \mathrm{Er}_{0.04} \mathrm{Sm}_{0.03} \mathrm{Yb}_{0.03}\right) \Sigma_{1.01}\left(\mathrm{PO}_{4}\right)$. Более темные участки характеризуются меньшим содержанием этих элементов и отвечают формуле $\left(\mathrm{Y}_{0.81} \mathrm{Gd}_{0.07} \mathrm{Dy}_{0.07} \mathrm{Er}_{0.03} \mathrm{Yb}_{0.02} \mathrm{Sm}_{0.01}\right)$ $\Sigma_{1.01}\left(\mathrm{PO}_{4}\right)$.

Наиболее распространенными представителями данного класса являются минералы групnы монацита, а именно монацит- $(\mathrm{Ce}) \mathrm{Ce}\left(\mathrm{PO}_{4}\right)$ и монацит- $(\mathrm{Nd}) \mathrm{Nd}\left(\mathrm{PO}_{4}\right)$. Они встречаются во всех типах руд, в разных ассоциациях. Одной из наиболее часто встречаемых является ассоциация монацита с ванадийсодержащим мусковитом в альбите, в реликтах кварц-альбитовых жил (рис. 1 в, г; рис. 2 а-г). Могут присутствовать сидерит, шамозит, минералы группы эпидота, кричтонита, Ti-V оксиды, тортвейтит.

В химическом составе обычно доминирующим катионом является Се или $\mathrm{Nd}, \mathrm{La}$ на третьем месте, что хорошо отражает тройная диаграмма видового разнообразия минералов группы монацита и эволюции их состава (рис. 1 д). Часто встречаются индивиды, в которых содержания этих элементов практически равны. Постоянно в качестве примеси, кроме других REE ( $\mathrm{Sm}, \mathrm{Pr}, \mathrm{Gd})$, присутствуют железо (до 2 мас. \% $\mathrm{Fe}_{2} \mathrm{O}_{3}$ ) и торий (до 3 мас. \% $\mathrm{ThO}_{2}$ ). В целом, формулы монацита-(Cе) и монацита-(Nd) соответственно выглядят следующим образом:

$$
\begin{aligned}
& \left(\mathrm{Ce}_{0.40} \mathrm{Nd}_{0.24} \mathrm{La}_{0.19} \mathrm{Fe}_{0.06} \mathrm{Pr}_{0.05} \mathrm{Sm}_{0.05} \mathrm{Gd}_{0.02} \mathrm{Th}_{0.02}\right)_{\Sigma 1.04} \mathrm{P}_{0.97} \mathrm{O}_{4} \\
& \left(\mathrm{Nd}_{0.42} \mathrm{Ce}_{0.22} \mathrm{Sm}_{0.10} \mathrm{La}_{0.09} \mathrm{Pr}_{0.08} \mathrm{Fe}_{0.05} \mathrm{Gd}_{0.04} \mathrm{Dy}_{0.04} \mathrm{Th}_{0.02}\right)_{\Sigma 1.06} \mathrm{P}_{0.96} \mathrm{O}_{4}
\end{aligned}
$$

Монациты не проявляют заметную фазовую или внутрифазовую неоднородность. Монацит в ассоциации с другими Y-REE минералами довольно часто встречается в колчеданных рудах Кольского региона, в том числе в Панареченской структуре [2].
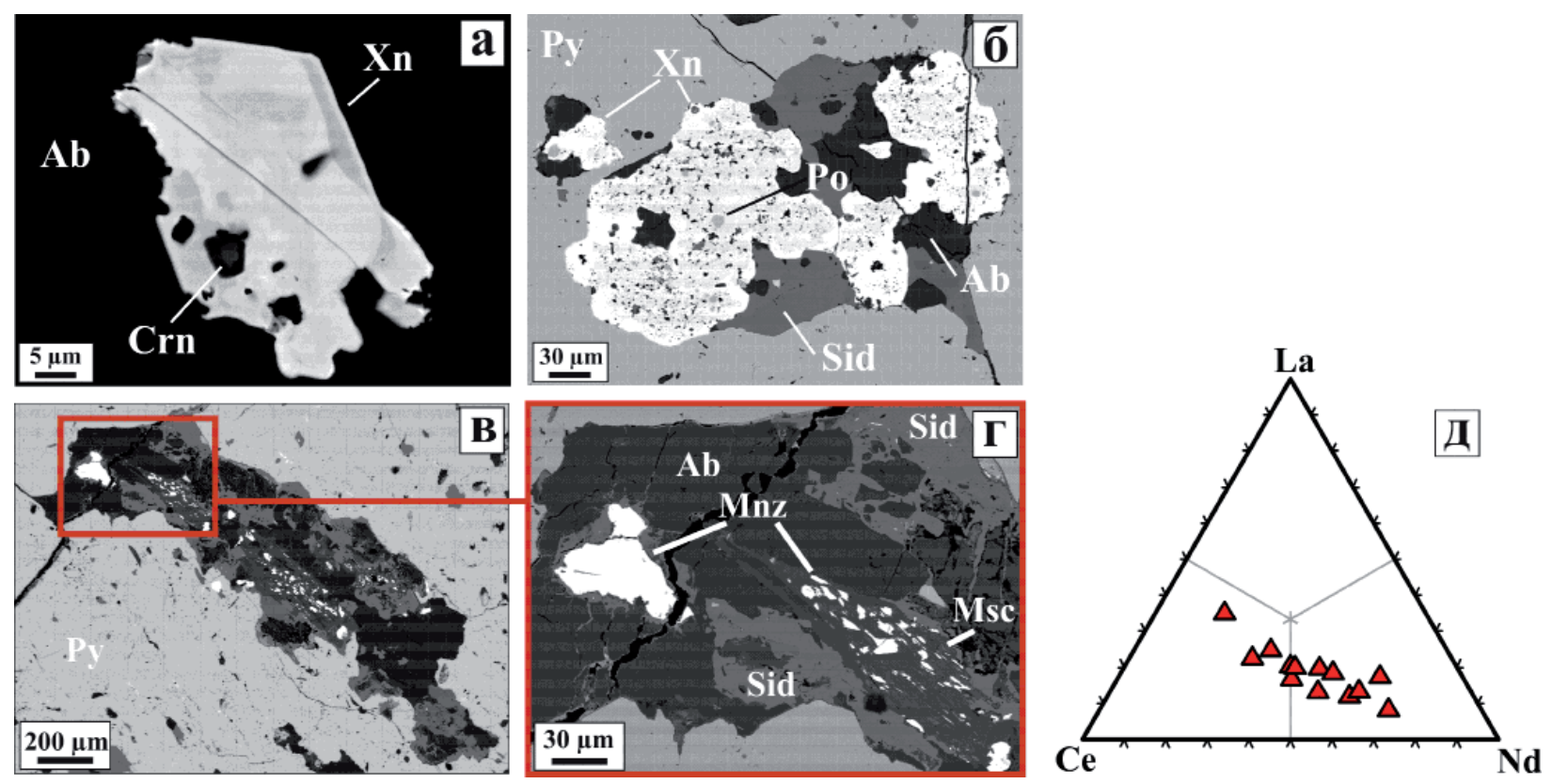

Рис. 1. Морфология и ассоциация фосфатов REE в колчеданных рудах Брагино.

a - фазовая и внутрифазовая неоднородность в ксенотиме (Xn); б - пойкилитовый агрегат ксенотима с многочисленными включениями сульфидов и нерудных минералов; в, г- ванадийсодержащий мусковит (Мsc), насыщенный мелкими включениями монацита (Mnz) и более крупное отдельное выделение монацита. BSE снимки. д - тройная диаграмма видового разнообразия минералов группы монацита. Ру - пирит; Po - пирротин; Crn - минерал группы кричтонита; Sid - сидерит; Ab - альбит. 


\section{Силикаты Y-Ln}

В колчеданных рудах участка Брагино, в пиритовых рудах внутри кристаллов пирита установлены обособления, содержащие в себе ассоциацию ванадийсодержащих силикатов: алланита, мусковита и хлорита, а также монацита-(Nd) и монацита-(Се) (рис. 2 a-г).
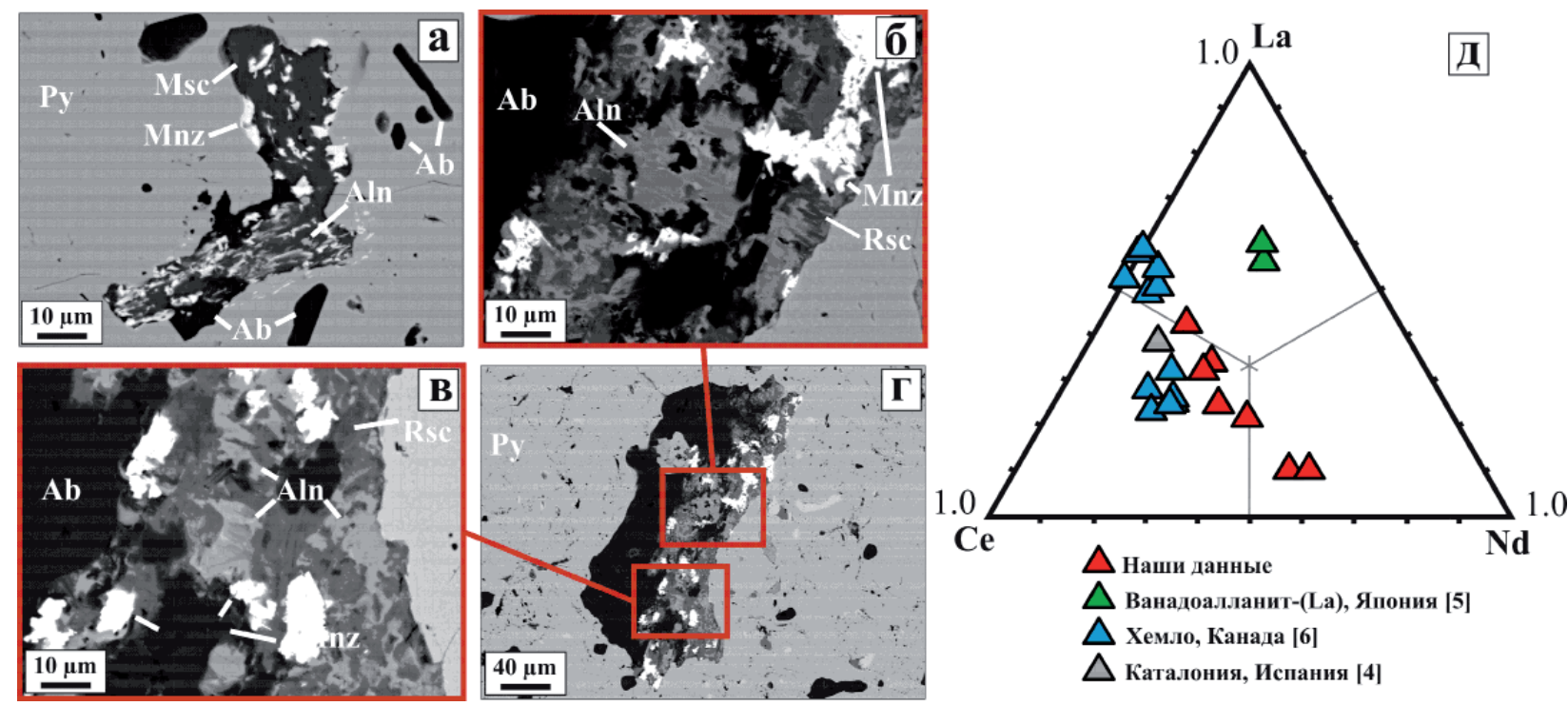

Рис. 2. а-г - ванадийсодержащие REE-минералы группы эпидота (подгруппы алланита, Aln) в колчеданных рудах участка Брагино в ассоциации с ванадийсодержащим мусковитом (Msc), роскоэлитом (Rsc), монацитом (Mnz) и альбитом (Ab) в пиритовых рудах (Рy); BSE снимки; д - тройная диаграмма видового разнообразия минералов подгруппы алланита из разных месторождений.

Таблица. Распределение катионов в минералах подгруппы алланита из колчеданного проявления Брагино.

\begin{tabular}{|c|l|l|l|l|}
\hline & \multicolumn{1}{|c|}{$\mathbf{1 2}$} & \multicolumn{1}{|c|}{$\mathbf{M 1}$} & \multicolumn{1}{|c|}{$\mathbf{M 2}$} & \multicolumn{1}{c|}{$\mathbf{M 3}$} \\
\hline 1 & $\left(\mathbf{C e}_{0.23} \mathrm{La}_{0.19} \mathrm{Nd}_{0.15}\right)_{\Sigma 0.57}$ & $\left(\mathbf{V}_{0.67} \mathrm{Al}_{0.31} \mathrm{Cr}_{0.02}\right)_{\Sigma 1.00}$ & $\mathbf{A l}_{1.00}$ & $\left(\mathbf{F e}_{0.38} \mathrm{Al}_{0.24} \mathrm{Mg}_{0.14}\right)_{\Sigma 0.76}$ \\
\hline 2 & $\left(\mathbf{N d}_{0.31} \mathrm{Ce}_{0.19} \mathrm{La}_{0.06} \mathrm{Sm}_{0.09}\right)_{\Sigma 0.65}$ & $\left(\mathbf{V}_{1.00} \mathrm{Cr}_{0.14} \mathrm{Sc}_{0.02}\right)_{\Sigma 1.16}$ & $\mathbf{A l}_{1.00}$ & $\left(\mathbf{F e}_{0.66} \mathrm{Al}_{0.27} \mathrm{Mg}_{0.08}\right)_{\Sigma 1.01}$ \\
\hline 3 & $\left(\mathbf{N d}_{0.33} \mathrm{Ce}_{0.23} \mathrm{Sm}_{0.08} \mathrm{La}_{0.07} \mathrm{Pr}_{0.07}\right)_{\Sigma 0.78}$ & $\left(\mathbf{V}_{0.86} \mathrm{Al}_{0.08} \mathrm{Cr}_{0.06}\right)_{\Sigma 1.00}$ & $\mathbf{A l}_{1.00}$ & $\left(\mathbf{F e}_{0.68} \mathrm{Al}_{0.17} \mathrm{Mg}_{0.15}\right)_{\Sigma 1.00}$ \\
\hline 4 & $\left(\mathbf{C e}_{0.35} \mathrm{La}_{0.27} \mathrm{Nd}_{0.21}\right)_{\Sigma 0.83}$ & $\left(\mathbf{V}_{1.01} \mathrm{Cr}_{0.04}\right)_{\Sigma 1.05}$ & $\mathbf{A l}_{0.98}$ & $\mathrm{Fe}_{1.04}$ \\
\hline
\end{tabular}

Примечание. Жирным выделены доминантные катионы в соответствующей позиции. Распределение произведено в соответствии с предположением, что наши минералы могут быть аналогами ванадоалланита-(La) $(\mathrm{CaLa})\left(\mathrm{V}^{3+} \mathrm{AlFe}^{2+}\right)\left(\mathrm{Si}_{2} \mathrm{O}_{7}\right)\left(\mathrm{SiO}_{4}\right) \mathrm{O}(\mathrm{OH})$.

Предполагаемые формулы минералов:

1. $\mathrm{Ca}_{1.65}\left(\mathbf{C e}_{0.23} \mathrm{La}_{0.19} \mathrm{Nd}_{0.15}\right)_{\Sigma 0.57}\left(\mathbf{V}_{0.67} \mathrm{Al}_{0.31} \mathrm{Cr}_{0.02}\right)_{\Sigma 1.00} \mathbf{A l}_{1.00}\left(\mathbf{F e}_{0.38} \mathrm{Al}_{0.24} \mathrm{Mg}_{0.14}\right)_{\Sigma 0.76}\left(\mathrm{Si}_{2} \mathrm{O}_{7}\right)\left(\mathrm{SiO}_{4}\right) \mathrm{O}(\mathrm{OH})$

2. $\left(\mathrm{Ca}_{1.08} \mathrm{Mn}_{0.07}\right)_{\Sigma 1.15}\left(\mathbf{N d}_{0.31} \mathrm{Ce}_{0.19} \mathrm{La}_{0.06} \mathrm{Sm}_{0.09}\right)_{\Sigma 0.65}\left(\mathbf{V}_{1.00} \mathrm{Cr}_{0.14} \mathrm{Sc}_{0.02}\right)_{\Sigma 1.16} \mathbf{A l}_{1.00}\left(\mathbf{F e}_{\mathbf{0 . 6 6}} \mathrm{Al}_{0.27} \mathrm{Mg}_{0.08}\right)_{\Sigma 1.01}\left(\mathrm{Si}_{2} \mathrm{O}_{7}\right)\left(\mathrm{SiO}_{4}\right) \mathrm{O}(\mathrm{OH})$

3. $\left(\mathrm{Ca}_{1.17} \mathrm{Mn}_{0.06}\right)_{\Sigma 1.23}\left(\mathbf{N d}_{0.33} \mathrm{Ce}_{0.23} \mathrm{Sm}_{0.08} \mathrm{La}_{0.07} \mathrm{Pr}_{0.07}\right)_{\Sigma 0.78}\left(\mathbf{V}_{0.86} \mathrm{Al}_{0.08} \mathrm{Cr}_{0.06}\right)_{\Sigma 1.00} \mathbf{A l}_{1.00}\left(\mathbf{F e}_{0.68} \mathrm{Al}_{0.17} \mathrm{Mg}_{0.15}\right)_{\Sigma 1.00}\left(\mathrm{Si}_{2} \mathrm{O}_{7}\right)\left(\mathrm{SiO}_{4}\right) \mathrm{O}(\mathrm{OH})$

4. $\left(\mathrm{Ca}_{1.07} \mathrm{Mn}_{0.03}\right)_{\Sigma 1.10}\left(\mathbf{C e}_{0.35} \mathrm{La}_{0.27} \mathrm{Nd}_{0.21}\right)_{\Sigma 0.83}\left(\mathbf{V}_{1.01} \mathrm{Cr}_{0.04}\right)_{\Sigma 1.05} \mathbf{A l}_{0.98} \mathbf{F e}_{1.04}\left(\mathrm{Si}_{2} \mathrm{O}_{7}\right)\left(\mathrm{SiO}_{4}\right) \mathrm{O}(\mathrm{OH})$

Химический состав минералов довольно переменчив. Содержание $\mathrm{V}_{2} \mathrm{O}_{3}$ колеблется в пределах от 8.58-13.74 мас. \%, редко в качестве примеси отмечается скандий. Согласно расчету кристаллохимических формул (табл.), как и в ванадоалланите-(La), $\mathrm{V}^{3+}$ в наших минералах может являться доминирующим в позиции M1, Al - в M2, а Fe ${ }^{2+}$ - в M3. Распределение катионов по позициям A2, M1, M2, M3 в формулах минералов дано в табл. Минералы могут быть аналогами ванадоалланита-(La), c доминирующими Се или $\mathrm{Nd}$ в структурной позиции $\mathrm{A} 2$ - ванадоалланит-(Се) и ванадоалланит-(Nd). Как видно из тройной диаграммы распределения катионов в позиции А2 (рис. 2), в химическом составе алланита из Брагино наблюдается тренд от Се к $\mathrm{Nd}$, тогда как в большинстве других подоб- 
ных минералах существенную роль играет La. Подобный тренд находит свое отражение и в химическом составе монацита - доминирующими чаще всего являются Се или $\mathrm{Nd}$, a $\mathrm{La}$ на третьем месте. В качестве примеси Y и ряд REE ( $\mathrm{Sm}, \mathrm{Nd}, \mathrm{Gd}, \mathrm{Dy}, \mathrm{Er}, \mathrm{Yb})$ установлены так же в тортвейти$m e \mathrm{Sc}_{2} \mathrm{Si}_{2} \mathrm{O}_{7}$ Наибольших концентраций достигают Y (до 6 мас. \% $\mathrm{Y}_{2} \mathrm{O}_{3}$ ), $\mathrm{Yb}$ (до 3.5 мас. \% $\mathrm{Yb}_{2} \mathrm{O}_{3}$ ), содержания остальных не превышают 1 мас. \%.

Присутствие Y-REE минералов и их приуроченность к реликтам кварц-альбитовых жил могут указывать на гидротермальное происхождение подобных образований. Так же прослеживается явная генетическая и пространственная связь данного типа минерализации c Cr-Sc-V типом, ранее установленным в колчеданных рудах Кольского региона [3].

Работа выполнена в рамках Госзадания ГИ КНЦ РАН (тема НИР № 0231-2015-0001) при частичной поддержке программы Президиума РАН № 19.

\section{Литература}

1. Ахмедов А.М., Вороняева Л.В., Павлов В.А. и др. Золотоносность Южно-Печенгской структурной зоны (Кольский полуостров): типы проявлений и перспективы выявления промышленных содержаний золота // Региональная геология и металлогения. 2004. № 20. С. 143-165.

2. Волошин А.В., Чернявский А.В., Войтеховский Ю.Л., Савченко Е.Э. Ү-REЕ минералы и минералы группы циркона из рудных зон Панареченской вулкано-тектонической структуры // Золото Кольского полуострова и сопредельных регионов. Тр. Всероссийской (с международным участием) научной конф., посвящённой 80-летию Кольского НЦ РАН. Апатиты. 2010. С. 11-13.

3. Карпов С.М., Волошин А.В., Компанченко А.А., Савченко Е.Э., Базай А.В. Минералы группы кричтонита в колчеданных рудах и рудных метасоматитах протерозойских структур Кольского региона // Записки РМО. 2016. № 5. С. 39-56.

4. Canet C., Alfonso P., Melgarejo J-C., Jorge S. V-rich minerals in contact-metamorphosed Silurian sedex deposit in the Poblet area, Southwestern Catalonia, Spain // The Canadian Mineralogist. 2003. V. 41. P. 561-579.

5. Nagashima M., Nishio-Hamane D., Tomita N., Minakawa T., Inaba S. Vanadoallanite-(La): a new epidotesupergroup mineral from Ise, Mie Prefecture, Japan // Mineralogical Magazine. 2013. V. 77(6). P. 2739-2752.

6. Pan Y., Fleet M.E. Vanadian allanite-(La) and vanadian allanite-(Ce) from the Hemlo gold deposit, Ontario, Canada // Mineralogical Magazine. 1991. N. 55. P. 497-507. 